\title{
Activities to teach heat and temperature concepts to visually impaired students
}

\author{
${ }^{1}$ Ağri İbrahim Çeçen University, Department of Special Education, Education Faculty Ağri, Turkey, E-mail: \\ ydnkizilaslan@gmail.com \\ ${ }^{2}$ Atatürk University, Department of Mathematics and Science Education, Kazim Karabekir Education Faculty, Erzurum, Turkey, \\ E-mail: sozbilir@atauni.edu.tr. orcid.org/0000-0001-6334-9080.
}

\begin{abstract}
:
Low vision or blindness are defined as visual impairment, which is the decreased ability to see to a degree that causes problems in education as well as in daily life. Students with visual impairment struggle with learning concepts in science due to using visual objects such as figures, equations and graphs. But the science could be made more accessible to those students through collaboration and specific adaptation in both the science classroom and laboratory by providing simple adaptations or doing some essential modifications to help them gaining experience with measuring, balancing and weighing a variety of materials with simple adaptations or modifications. This study aims to design activities to teach heat and temperature concepts to visually impaired students which are found difficult to comprehend even by the sighted students. For this purpose, instructional material that emphasizing the sense of touch and interactive science activities were designed to make science more accessible to 8 th grade students in a special school for visually impaired. The activities basically consist of simple, economical and easily accessible everyday materials. Nearly all of the students indicated that they are quite satisfied if all courses would be taught by activities developed in line with their individual needs.
\end{abstract}

Keywords: heat, science activity, temperature, visually impaired students

DOI: $10.1515 /$ cti-2018-0005

\section{Introduction}

Disability is a very broad concept. Despite the well-known disabilities such as mentally, physically, and orthopedically disability, there is a wide range in visual and hearing impairment. In recent years, the necessary amendments have been made in social, economic, education and accessibility rights of disabled people in many countries (Thomas \& Imrie, 2008).

Like every individual with impairment, students with visual impairment also face with many problems. Accessible classroom environment and curricula, teaching materials and assistive teaching technologies are core of these problems. For example, accessibility problems prevent reaching of the individuals with visual impairment to fundamental education (Arter, Mason, McCall, McLinden, \& Stone, 1999). Education aims to provide fundamental skills to students with any impairment to be a part of the society. However, individuals with visual impairment who are experiencing difficulties in accessing basic education do not have adequate levels of schooling in all levels of education and training.

Science education is the one of the core component of the basic education. It has a great importance in the development of children's scientific thinking skills, in their ability to answer scientifically the problems they encounter in daily life, in the development of problem solving skills, and in the growth of their experience and skills in life. Science education has been identified as one of the most useful and valuable areas of content for students with special needs by some special educators (Mastropieri \& Scruggs, 1995). In addition, science education can contribute to students' understanding of the world and their ability to form a scientific basis for the problems encountered in everyday life (Leong, 1993). In addition, science education has an important place in the development of problem-solving abilities and scientific attitudes, and in the enhancement of the experience and skills that recommended for the special educators, in the perception of the world, in making correct decisions in the direction of perceptions. It offers students the opportunity to experience rich experiences in order to understand the interrelationships of objects in the light of new ideas (National Research Council (NRC)., 1996). 
In addition, science education provides great opportunities for students to develop high-level thinking skills and problem-solving strategies (de Boer, Pijl, \& Minnaert, 2012). The efficiency of science education arises from well-prepared science activities. So, it is necessary to prepare the unique science activities for these students in accordance with the individual needs of the children. Science materials may include talking devices, tactile charts, reading materials, etc.

Traditionally science teaching mostly depends on visual instruction (Sözbilir, 2016; Supalo \& Kennedy, 2014). However distinction must be made between compensatory skills and functional skills so that students with visual impairments can access the expanded core curriculum in addition to the core academic curriculum of general education. Compensatory skills are those skills needed by students who are blind or visually impaired to access all areas of the general curriculum. Compensatory and functional skills include concept development, spatial awareness, keyboarding skills, listening skills, organizational skills, use of the abacus, or tactile discrimination skills (Holahan, McFarland, \& Piccillo, 1994). The curriculum framework sets out what a student with visual impairment should be able to do and the experiences that contribute to the learning needs of them. The curriculum should be balanced with due consideration given to the student's physical, social, emotional, linguistic and cognitive needs. To teach visually impaired children, the teacher should adopt a consistent, realistic and flexible approach in curriculum planning and implementation (Lohmeier, Blankenship, \& Hatlen, 2009).

Many concepts in science and mathematics have been found inaccessible to students with visual impairment due to use of figures, equations and graphs (Annable, Goggin, \& Stienstra, 2007; Kızılaslan \& Sözbilir, 2018; Sleeuwenhoek, Boter, \& Vermeer, 1995). Teachers can make the world of science more accessible to students with visual impairments through collaboration and specific adaptations in both the science classroom and laboratory by providing students with a variety of opportunities to explore and examine real materials closely or use models (Hadary \& Cohen, 1978; Lang, 1983). Consideration of the following suggestions may improve the science achievement of students with visual impairment: (Abruscato, 1996; Ricker \& Rodgers, 1981).

1. Give priority to students to use two-handed exploration to get a sense of scale and how parts of the object relate to each other.

2. Keep in mind whether a model reflects the texture of the actual object and descriptions of the model understandable.

3. Simplify diagrams to focus on the core concept and where appropriate delete unnecessary content.

4. Warn the students about the harmful equipment and materials.

5. Give the student a clear verbal explanation by a lab partner or by the teacher.

6. Use tactile equipment such as rulers and measuring tape, and talking timers, thermometers, balances and calculators.

7. Encourage and plan independent work so the learner builds the skills they willl need later for practical homework and coursework.

8. Give the student a clear verbal explanation by a partner

9. Describe and tactually familiarize the student to the classroom, laboratory, equipment, supplies, materials, etc.

10. Allow student to use a tape recorder for recording classroom presentations or the text.

In the light of these principles, activities and materials were developed for this study aimed to teach heat and temperature concepts which are found difficult to comprehend even by the sighted students. For this purpose, we have designed an activity based on using tactile materials for making science more accessible to students with visual impairment.

\section{Method}

The study consisted of two basic step. At the first step of the study, teaching materials and activities that is designed and developed in terms of students' learning needs. At the second step data about the implementation of the activities and then the opinions of the students about the activities are presented. The activities are basically consisting of simple, economical and easily accessible everyday materials. Participant of this activity were six students including a blind student. The ages of the sample group ranged from 14 to 16 years. 
Teaching materials or the implementation of the different methods at the instruction is important in teaching science. When considering the problems experienced in the teaching science concepts, the importance of the activity-based science teaching is constantly increasing. For this reason, Activity Based Instruction (ABI) has an important influence on science teaching. ABI which is used as a teaching method in this study uses child-friendly educational aids to enables students make judgments on a subject based on activities and observations, to foster self-learning and allows a child to study according to his or her aptitude and skills and to enhance the interactive interaction of the teacher with the student. ABI enables students to improve their reasoning and problem-solving skills and concept learning process. In order to enable students to establish a conceptual familiarity between activities and daily life, commonly used everyday life materials were used to design activities (Campbell \& Campbell, 2009). While student activity guide is being prepared in Century Gothic font with font size 18-20 for the students with low vision, for the blind students Braille documents were designed and used. According to the research done the Century Gothic fonts with at least 18 font was identified as the best readable font by visually impaired students (Çakmak, Karakoç, Şafak, \& Kan, 2014).

\section{Implementation}

At this step firstly the data on the implementation of the activity designed for teaching the heat concept and then the temperature concept will be presented. The following standards were set while the activities were implemented:

1. The existing knowledge of the students was tried to be elaborated before each activity.

2. Enough time was given to each student to investigate the activity materials by touching.

3. Student activity guide were distributed for each student before the activity.

4. The teacher allowed students to do each activity on his own.

5. Student safety is emphasized at every stage and precautions were told initially.

6. Students' active involvement was reinforced to learn concepts better.

7. Students were taken note about each concept at the end of the activity.

The first activity described below was designed to teach the heat concept (Table 1). The activity is aimed at concept teaching by combining inquiry-based skills and activities.

Table 1: Activity for the heat concept

Student activity guide

Name of the activity:

How does heat transfer?

Materials:

Cold water

Warm water

$500 \mathrm{~mL}$ plastic water bottle

Let's make the activity

1. Fill one of the pet bottles with cold water and the other with warm water

2. Prepare one for each student

3. Help students to hold warm water with one hand and cold water with the other hand

4. Let's feel the cold water and warm water for $2 \mathrm{~min}$

5. Let's discuss why one of the our hand is getting cold and the other is heating up?

Activity 1: Let's find the direction of heat transfer

Concept to learn: Heat

Definition of heat: Energy transferred from a hotter to a cooler body due to a temperature gradient.

Implementation of the activity: The following questions were asked about the heat transfer in order to activate the preliminary knowledge of the students before the activity.

$\checkmark$ Why does a cup of hot tea cool after a while? 
$\checkmark$ How do thick clothes that we wear in winter keep our body temperature?

After these questions, the activity was held. It was emphasized that the aim of the activity is to teach the concept of heat transfer. The activity is designed to allow students to distinguish the concepts of heat and temperature. During the activity it is emphasized that heat is an energy transferred from the warm substance to the cold substance due to the temperature difference between them.

All students have actively participated in pre and post activity questions. The following dialogue took place during the activity.

Teacher: Yes, I asked you a question at the beginning of the lesson. Why is the temperature of the cup increasing when filled with the warm water?

$\mathrm{S}_{2}$ : The temperature is transferred from the warm substance to the cold substance

Teacher: Temperature?

$\mathrm{S}_{3}$ : No: it should be heat

Teacher: Yes, ...

$\mathrm{S}_{5}$ : When a warm substance come in contact with a cold substance, the heat transferred occur between them (Figure 1)

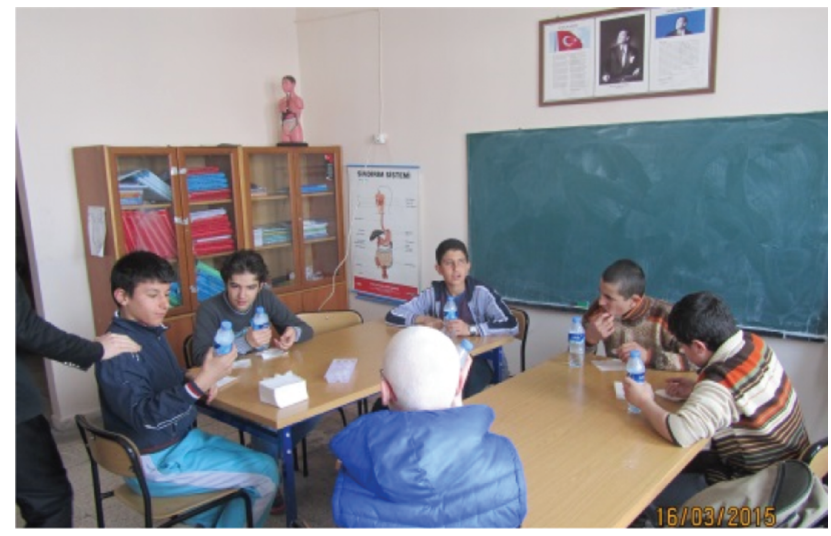

Figure 1: Presenting of the activity materials.

Teacher: Does the heat transfer take place between warm substance to cold or from cold to warm?

$\mathrm{S}_{6}$ : From warm to cold

Teacher: Do everyone agree?

Students: Agree

Students were able to feel that the heat is transferred from warm substance to cold substance through touching (Figure 2).

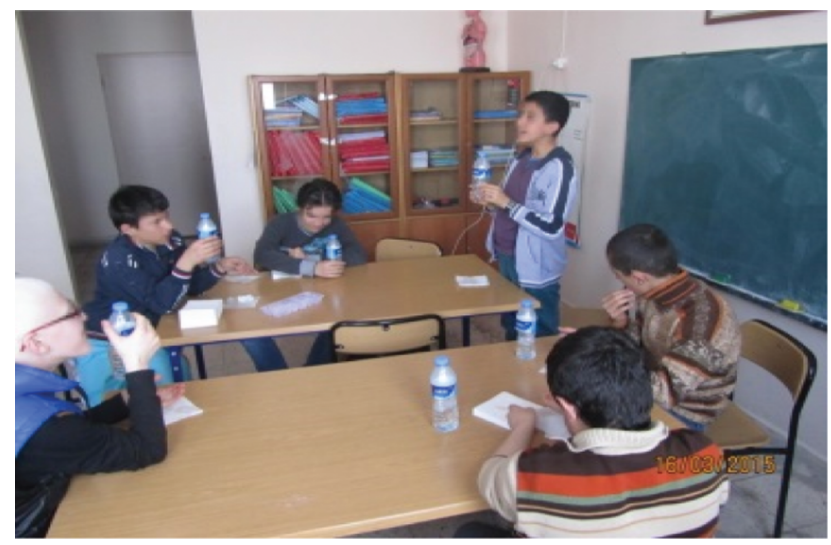

Figure 2: Discussion of temperature change.

The second activity described below was designed to teach the temperature concept (Table 2). The activity is aimed to teach temperature concept by combining the questioning-based skills and observation data.

Table 2: Activity for the temperature concept 


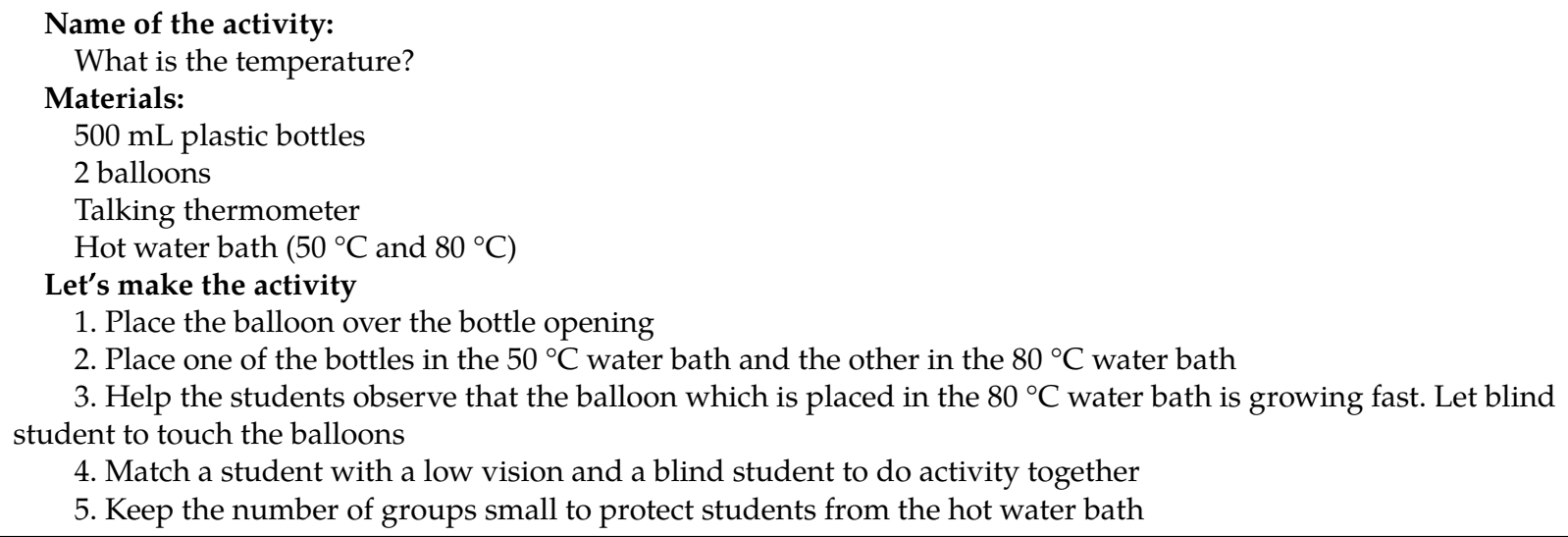

Activity 2: Kinetic energy and temperature

Concept to learn: Temperature

Definition of heat: Temperature is the measurement of hotness or coldness of a body. It is not energy. Energy is associated with microscopic motion of the particles analyzed. It can be expressed in degree Celsius, Kelvin, and Fahrenheit.

Implementation of the activity: First, explain the purpose of the activity to the students. Emphasize that the purpose of the activity is to show how the temperature of the particle effects the growing of the balloons. Ask students the following questions using the brain storm technique to motivate students before activity.

$\checkmark$ We learned that heat was an energy transferred due to temperature difference between the bodies in the previous session. Then, how does the movement of particles of a substance change when heated? And How do we observe a change in the particles of a substance that receives heat?

The following dialogs indicates the discussions took place between the teacher and the students:

Teacher: Yes, does the movement of particles of a substance that takes heat increase or decrease? Who will answer? Mr.

$\mathrm{S}_{2}$ : As a substance gets hotter, it gets hotter and hotter; I think the distance between the particles increases

$\mathrm{S}_{1}$ : for example, when we put hot water in a cold glass, the hot water cools

Teacher: okay, anyone else?

$\mathrm{S}_{3}$ : For example, $\mathrm{Mr}$, the ice is solid. When we heat it, it becomes liquid. The motion of the particles increases, result the liquid moves.

Teacher: Yes, anyone else?

$\mathrm{S}_{4}: \mathrm{Mr}$, I think that if the temperature of a substance increases, the distance of the particles increases.

All activity materials were introduced to the students one by one before the activity. Blind student is provided with perception of materials by touching.

The aim of the activity is to teach the concept of temperature by comparing the swelling of the balloons with different amounts of heat transferred them by putting bottles in different temperature water baths. Students have been given enough time to feel the warmth of the water by touching it (Figure 3). The bottles were then placed in baths. During this period, it was observed by the students that the balloon in the $80^{\circ} \mathrm{C}$ hot water bath swelled fast (Figure 4). The students were questioned about why the balloon at the $80^{\circ} \mathrm{C}$ bath swelled fast by linking the first activity. 


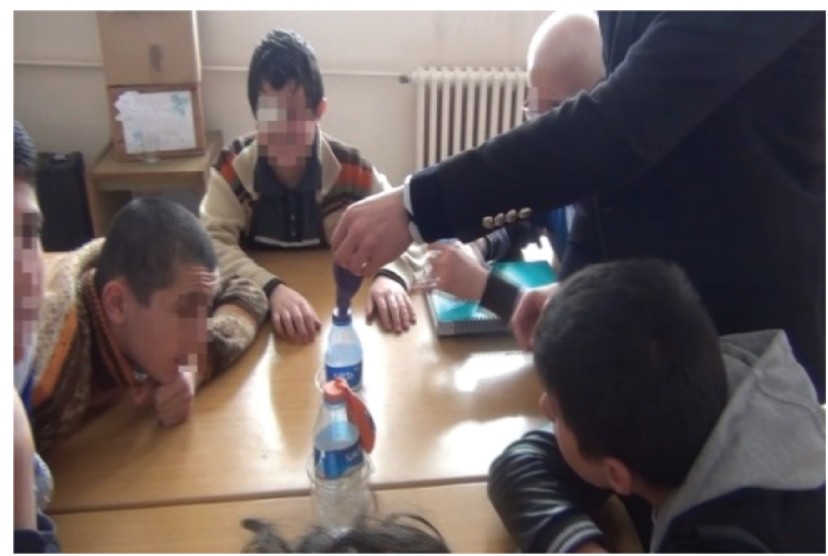

Figure 3: Informing about the activity.

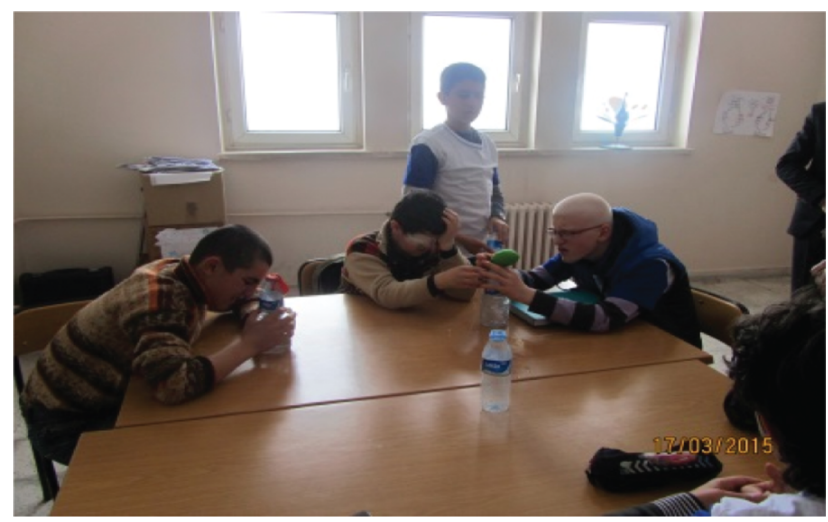

Figure 4: Performing of the activity.

During the activity, it was emphasized that due to the more energy transfer from the hot water to the bottles, the motion of the air particles in the plastic bottles began to increase and thus the particles began to move fast and hit the walls of the balloons too. The increase in the motion of the air particles, caused swelling of the balloons. However, one of the balloon swelling was quicker than the other. This was because the fast swelling balloon was set into hotter water than the other. This could be considered more increase in the temperature of the air in the bottle. Students are also allowed to observe this by touching the bottles.

All students were actively involved in the questions at the end of the activity.

Teacher: yes ... who will now define the temperature?

$\mathrm{S}_{2}$ : If we warm up a substance, the particles move, for example, let us think about the ice. When we warm the ice and the water particles tends to move more.

S1: Mr, after heating any substance, the temperature increases.

Teacher: Then is there a relationship between the increase in temperature and the motion of particles?

$\mathrm{S}_{6}: \mathrm{Mr}$, the movement of the particles is increasing with the heat. That is, the temperature increase indicates to us that the motion of the particles increases.

$\mathrm{S}_{5}$ : More energy was transferred to particles from hot water to bottles

Teacher: Because the particles with increasing temperature moved more. These moving particles caused the balloon in the hot water tank to swell more.

In interviews with students about the activities, the students stated that the activities useful, impressive, easy, understandable, memorable, and were related to the topic and facilitated their learning. They also stated that the fact that the activities are related to the subject matter positively affects the remembrance of the concept and the subject. The descriptive analyses of the students' opinions about the activities are given below:

$\mathrm{S}_{1}$ : The activities were very useful. The points that were useful were $\mathrm{mmm}$ we had no experience of heat transfer. We put some hot water and cold water to the bottles. On the one hand it was heat transfer to the cold bottle. On the other hand, this time it was a heat transfer from our hands to the bottle. An awesome experience

$\mathrm{S}_{2}$ : The activities were very easy to understand and very entertaining. The events were very easy to understand and joyfull. .... I can say they are very useful because it is our first experience. We have never had such activities before. The activities we have done have not been very instructive. 
$\mathrm{S}_{3}$ : I can say that the activities are very useful because they are about the lessons we are studying. The activities related heat, heat transfer and temperature concepts were very instructive. Our teacher explained these concepts after activities. I think we learned better

$\mathrm{S}_{4}$ : It is worth remembering that the activities are useful. For example, if we read a question about that topic, we can say it in a proven way that we have done an activity related that this topic, so the reminiscence is really nice

$\mathrm{S}_{5}$ : The activities were all useful, easy and clear. I enjoyed the activities very much. For example, in the temperature experiment, we could observe by touching even if we could not observe with our eyes.

$\mathrm{S}_{6}$ : All activities were related to the topic and very useful. Pre- activity questions made it easier to understand the purpose of the events. The activity materials are not so expensive.

\section{Results and discussion}

Students with visual impairments need variety of accommodation to explore and examine real materials or models together with some adaptations in the environment in order to let students having safe and full access to science. It was concluded that in this study the activities and materials that is prepared and designed according to students' priority can successfully take place, if appropriate teaching method is adopted. Differences in teaching methods in terms of the students' needs are one of the most important adaptations when we considering how to make science accessible to the visually impaired students (Kumar, Ramasamy, \& Stefanich, 2001). The person with visual impairment can access the knowledge through many senses including touch, hearing, smell and taste during the teaching process, the teaching methods that based on these senses are important for meeting students' unique needs (McGrail \& Rieger, 2013). Thus, there is a need for a variety of adaptations and improvements in science teaching for individuals with visual impairment (Kızılaslan \& Sözbilir, 2017). Some of the core adaptations and improvements can be sorted as:

- Students with visual impairments use other senses at different level depending on the degree of visual impairment. Taking into consideration the students' individual scientific knowledge can be facilitated by bringing different senses to the forefront in the process of education.

- The activity should basically consist of simple, economical and easily accessible everyday materials.

- The students should be questioned through inquiry based questions before the activities began.

- Any material that is to be used before the activities requiring heating operations should be introduced to the students. Precautions should be taken against the hazards that may occur in the activities and students should be informed about these hazards.

- Students should be motivated to do activities on their own at individual activities. In addition, excessive use of reinforcements may lead to loss of motivation, so it is necessary to adjust the reinforcements very well.

- The active participation of all students should be ensured in the result part of the activities. So that the effect of knowledge persistence and effectiveness on the teaching of concepts can be achieved.

- The emphasis should not be placed on the individual differences of the students while the activities are taking place. Care must be taken during the activities to avoid using words such as "cannot you do it again?" you are too far behind" and etc.

\section{Conclusion}

Students who are blind or have low vision can participate in experiments and gain experience with measuring, balancing and weighing a variety of materials when provided with simple material adaptations or modifications. Taking into consideration the individual needs of the students, it is possible to facilitate the scientific knowledge achievement of the individuals by simple and effective activities and materials prepared for students with visual impairment by putting different senses into the foreground during the education process. Since the standardized curriculum is implemented in schools in our country, the individual needs of the students with visual impairment are often overlooked. Students should be able to learn the basic concepts through an activity-based teaching by reducing the outcomes of the curriculum. 


\section{References}

Abruscato, J. (1996). Teaching children science: A discovery approach. Boston, MA: Allyn \& Bacon.

Annable, G., Goggin, G., \& Stienstra, D. (2007). Accessibility, disability, and inclusion in information technologies: Introduction. Information Society, 23(3), 145-147.

Arter, C., Mason, H. L., McCall, S., McLinden, M., \& Stone, J. (1999). Children with visual impairment in mainstream settings. London: David Fulton Publishers.

Campbell, L. \& Campbell, M. (2009). Mindful learning: 101 proven strategies for student and teacher success. Thousand Oaks, CA: Corwin Press

Çakmak, S., Karakoç, T., Şafak, P., \& Kan, A. (2014). Identifying the reading speed of low vision student's at elementary level. International Journal in IT \& Engineering, 2(10), 38-48.

de Boer, A., Pijl, S. J., \& Minnaert, A. (2012). Students' attitudes towards peers with disabilities: A review of the literature. International Journal of Disability, Development and Education, 59(4), 379-392.

Hadary, D. \& Cohen, S. (1978). Science activities for blind, deaf, and emotionally disturbed students. College Park, MD: University Park Press.

Holahan, G. G., McFarland, J., \& Piccillo, B. A. (1994). Elementary school science for students with disabilities. Remedial and Special Education, 15(2), 86-93.

Kızılaslan, A. \& Sözbilir, M. (2017). Analysis of an activity designed for students with visual impairment according to science process skills. SDU International Journal of Educational Studies, 4(2), 86-95.

Kızılaslan, A. \& Sözbilir, M. (2018). Cörme yetersizliği olan öğrencilere yönelik tasarlanan etkinliklerin değerlendirilmesi: Isı alışverişi ve sıcaklık değişimi. Erzincan Üniversitesi Ĕ̆itim Fakültesi Dergisi, 20(1), 121-139.

Kumar, D., Ramasamy, R., \& Stefanich, C. (2001). Science for students with visual impairments: Teaching suggestions and policy implications for secondary educators. Electronic Journal of Science Education, 5(3). Article 4. Retrieved from https://ejse.southwestern.edu/article/view/7658.

Lang, H. G. (1983). Preparing science teachers to deal with handicapped students. Science Education, 67(4), 541-547.

Leong, C. K. (1993). Towards an applied cognitive science perspective in education. International Journal of Disability, Development and Education, $40(1), 63-73$.

Lohmeier, K., Blankenship, K., \& Hatlen, P. (2009). Expanded core curriculum: 12 years later. Journal of Visual Impairment \& Blindness, 103, 103112.

Mastropieri, M. A. \& Scruggs, T. E. (1995). Teaching science to students with disabilities in general education settings. Teaching Exceptional Children, 27(4), 10-13.

McCrail, E. \& Rieger, A. (2013). Increasing disability awareness through comics literature. Electronic Journal for Inclusive Education, 3(1), 1-21.

National Research Council (NRC). (1996). National science education standards. Washington DC: National Academy Press.

Ricker, K. S. \& Rodgers, N. C. (1981). Modifying instructional materials for use with visually impaired students. The American Biology Teacher, 43(9), 490-501.

Sleeuwenhoek, H. C., Boter, R. D., \& Vermeer, A. (1995). Perceptual-motor performance and the social development of visually impaired children. Journal of Visual Impairment, 89(4), 359-367.

Sözbilir, M. (2016). Practical work in science with visually impaired students. In I. Eilks, S. Markic, \& B. Ralle (Eds.), Science education research and practical work (pp. 169-179). Aachen: Shaker Verlag.

Supalo, C. A. \& Kennedy, S. H. (2014). Using commercially available techniques to make organic chemistry representations tactile and more accessible to students with blindness or low vision. Journal ofChemistry Education, 91(10), 1745-1747.

Thomas, H. \& Imrie, R. (2008). The interrelationships between environment and disability. Local Environment, 13, 477-483. 